

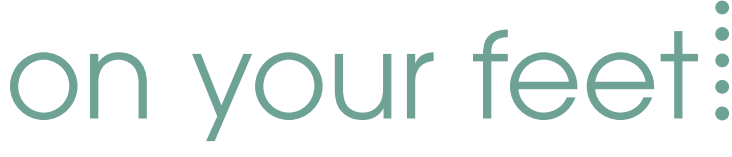

$\mathrm{T}$ his little piggy went to market, this little piggy stayed at home... do you remember that?

I would chuckle with glee as that last little piggy went wee wee wee... but somehow I don't think I'd be quite so delighted today if someone were to take hold of one of my toes and gave it a wiggle. That's not just because I'd be raising concerns of personal space, but as much because I would need at least three weeks' notice to get my feet into any kind of state that I'd be happy for anyone to take more than a passing glance at!

Okay... I put my hand up to almost total neglect of anything below my knees between the months of October and May, but I'm sure I'm not alone, and looking after your feet is even more important if you have a job where you are standing up most of the time. So I decided to investigate what it is we should be doing to keep our feet fit and healthy, and ready, at a moment's notice, for a pair of strappy slingbacks or a game of 'this little piggy'.

'The most common piece of advice we give to patients', says chiropodist Junaid Ahmed, 'is about nails and how to cut them. It is important to keep them healthy to avoid fungal infections and ingrowing nails. The best thing is to cut them straight across; and rubbing tea tree oil into them keeps them strong and in a healthy condition.'

A common ailment for people who are on their feet all day is athelete's foot, so to help prevent this, Junaid recommends drying thoroughly between the toes after washing. This fungi likes damp conditions, which is a bit of a problem if you have sweaty feet. But don't worry, Junaid has a suggestion for this too: 'bathing the feet in warm water with either drops of tea tree oil, or salt every day for two to three weeks usually helps'.

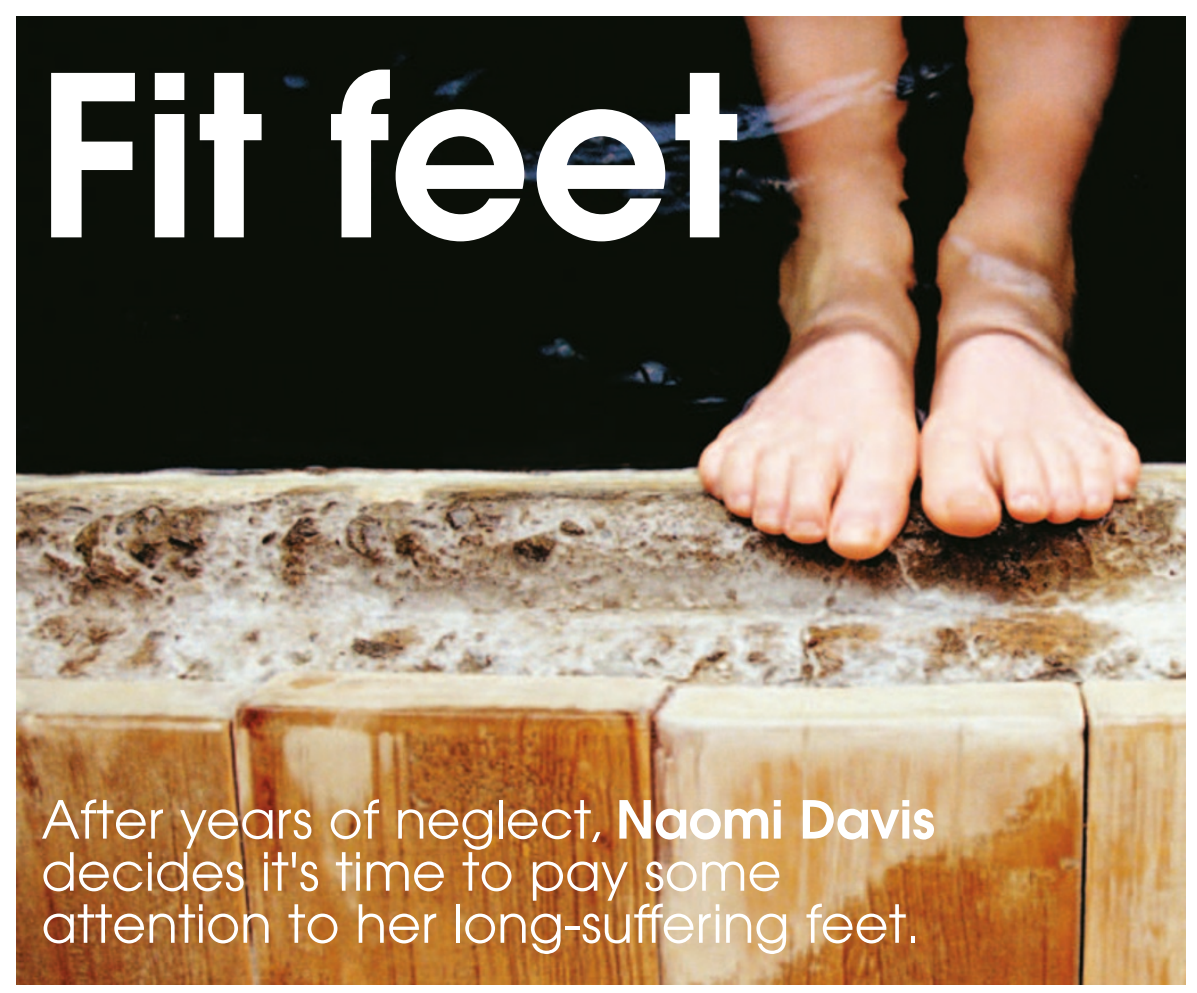

'Another area to watch out for is the heels'. If the skin gets very hard and dry they can become cracked and painful. Junaid goes to great lengths to point out that every day we moisturise our face and hands with special creams, and yet our feet, which are put under more stress than any other part of our bodies and dry out the most quickly, are given far less attention. 'Putting cream on the feet is a good idea, particularly if the skin is dry. For very bad heels a good idea is to, before going to bed, put cream on the feet, wrap them in clingfilm and then put on a thin pair of socks and leave on over night.'

For people who are on their feet for most of the day, it's a good idea not to stand still for too long, to try and keep the circulation going, stretch the legs, walk around and do a

\section{Doilly rouline}

To help keep your feet healthy, a daily routine is a good idea and the following steps are recommended by the Society of Chiropodists and Podiatrists:

Wash feet daily in warm soapy water and dry thoroughly particularly between the toes

Apply moisturising cream all over the foot (avoiding between the toes), especially in if the skin is dry. This will help to avoid cracked heels

Apply a light covering of powder

Use a pumice stone gently over hard skin but not on skin over a bony area or joint

Regularly trim toe nails using nail clippers. Cut straight across to avoid in-growing toe nails

Keep feet warm. Regular exercise helps to keep circulation healthy.

few exercises. Try going on to tiptoes a few times and flexing the feet.

Before we know it sandals season will be upon us again so I think it's time for me to put my neglectful habits behind me. If I follow this advice I might even be ready for a game of this little piggy...

\section{Wear the right shoes}

Always wear the right shoes for the job. Suitable shoes can protect against spillage, irritants and other substances. (BDA Advice Sheet, A3)

Wear well-fitting, comfortable shoes

Go for flexible soles, which should be flat except for a gentle slope up towards the toes

Fastenings needs to hold the foot in place and stop the toes from sliding. There should be enough room at the top for the toes to move freely

The lining of the shoe should be smooth, free from seams, wrinkles, rough or obstrusive stitching

The heel carries a large proportion of the body weight, so the heel of the shoe should have a broad base and be up to $4 \mathrm{~cm}$ high

The upper of a shoe should ideally be made of natural materials eg leather. 